\title{
A Theory of Development and Long Run Growth
}

\author{
by \\ Stephen Kosempel \\ Department of Economics and Finance, University of Guelph \\ kosempel@uoguelph.ca

\section{Department of Economics and Finance University of Guelph Discussion Paper 2001-05}

Accepted Manuscript@ Journal of Development Economics

(C) 2004, Elsevier. Licensed under the Creative Commons Attribution-Non Commercial-

No Derivatives 4.0 International http://creativecommons.org/licenses/by-nc-nd/4.0/

The final publication of this article is available at www.elsevier.com

DOI: http://dx.doi.org/10.1016/j.jdeveco.2003.08.004 


\title{
A theory of development and long run growth
}

\author{
Stephen Kosempel* \\ University of Guelph, Department of Economics, \\ Guelph, Ontario, N1G 2W1, Canada
}

\begin{abstract}
This paper presents a synthesized theory of development and long run growth. The theory that is presented combines two engines of growth which have been emphasized in the literature: technological progress and human capital accumulation. In the model, the growth rate of per capita output depends in part on the interaction between these two types of economic forces.

JEL classification: 011, 030, 040
\end{abstract}

Keywords: Human capital accumulation, technological change, economic growth

*Tel: (519) 824-4120 Ext. 53948; Fax: (519) 763-8497; Email: kosempel@uoguelph.ca 


\section{Introduction}

This paper presents a synthesized theory of development and long run growth. The theory that is presented combines two engines of growth which have been emphasized in the literature: technological progress and human capital accumulation. In the model, the growth rate of per capita output depends in part on the interaction between these two types of economic forces. A nice feature of the model is that it permits a tractable analysis of human and physical capital accumulation and total factor productivity (TFP) in the growth process.

To preview the model, technological progress shows up as quality improvements for an array of existing kinds of intermediate-capital goods. In the early phases a new technology may not be operated efficiently due to a lack of experience. However, labor can augment their productivity by devoting time to learning, that is, by accumulating human capital. It is assumed that the rate of human capital accumulation is positively related to both the amount of time spent learning and also the availability of learning opportunities. The latter is approximated using the ratio of the state of technology to the existing stock of human capital. The introduction of a new technology increases this ratio, that is, new technologies are assumed to create new opportunities for learning.

The setup of the model will be shown to produce dynamics for per capita output, TFP, and human and physical capital accumulation that are consistent with at least four stylized facts. These facts, and the model's 
explanation for them, will be discussed in the remainder of this section. The first stylized fact, listed below as Observation 1, defines the concept of development, as the process by which poor countries catch up to wealthy countries in terms of their per capita incomes. The remaining three facts, listed as Observations 2, 3 and 4, identify the macroeconomic variables that contribute to growth during various stages of economic development.

Observation 1: The empirical evidence supports conditional convergence, which suggests that countries with similar preferences and technologies should converge to the same level and growth rate of per capita income (see Mankiw, Romer, Weil, 1992; Barro and Sala-i-Martin, 1991, 1992). However, despite a tendency to converge, countries do not always follow a common path during the transition period. Some countries grow quickly during the early years of development, and then their growth slows as they approach the steady state. Other countries start off growing slowly, and then experience a relatively short period of very rapid growth.

In the model, output growth is high when the marginal product of physical capital is high, and this is because agents will be investing heavily, and therefore physical capital will be accumulating rapidly. The marginal product of physical capital is positively related to the stock of human capital, since this determines how effective workers are at operating capital goods; and negatively related to the stock of physical capital, since all inputs into the production function are assumed to have diminishing marginal products. The 
model will demonstrate that two countries can have the same income level, but due to differences in the composition of their capital stock, they experience different growth rates. The country with the larger endowment of human capital will grow the fastest initially. However, as it accumulates physical capital, the marginal product of its physical capital falls and output growth slows. In comparison, the country with the larger endowment of physical capital will experience slow growth in output and physical capital initially, but will accumulate human capital quickly. As this economy accumulates human capital, the marginal product of its physical capital rises and output growth increases. Although these economies experience different transitional dynamics, if they have the same preferences and technologies, they will both converge to a common balance growth path. Here they will be identical with respect to both their level and growth rate of per capita income.

In the sense that both human and physical capital play a role in the development process, the model is similar to the (human capital) augmented Solow model of Mankiw, Romer and Weil (1992). In both their paper and this one, the rate of human and physical capital accumulation can be linked to the marginal products of these factors. However, in the current paper much of the transitional dynamics are explained by having an endogenously determined and country specific rate of TFP growth. In comparison, the rate of productivity growth in the Mankiw, Romer and Weil paper is exogenous and assumed to be identical for all countries. The next two stylized facts provide support to modeling TFP as an endogenous variable. 
Observation 2: Islam (1995) provides evidence that there is a close relationship between the initial level of TFP and the initial level of human capital. Islam also found that higher levels of TFP are associated with higher levels of per capita income and also higher growth rates.

Observation 3: Benhabib and Spiegel (1994) found that the growth grates of physical capital and output have a statistically significant and positive correlation with human capital stocks, but a statistically insignificant and usually negative relationship with human capital growth.

Aghion and Howitt (1998) interpret the results of Islam and Benhabib and Spiegel as suggesting that when explaining the historical experience of developing economies one requires models in which TFP differs across countries and human capital promotes catching up. Following the suggestion of Aghion and Howitt and the work of Nelson and Phelps (1966), in the current paper the production function residual will be assumed to depend positively on the stock of human capital, and negatively on the sophistication of existing technology. Combined these assumptions imply that new technologies will not be operated efficiently until an investment in learning is undertaken. The model explains the empirical observations of Islam and Benhabib and Spiegel as follows: A large stock of human capital is associated with high productivity levels in production but low productivity levels in learning. As a result, physical capital and output grow quickly, but human capital accumulates slowly. 
Observation 4: Greenwood, Hercowitz and Krusell (1997) have found that in order to sustain growth in the long run the U.S. economy has relied on improvements in the technologies embodied in capital (or investment-specific technological change). In comparison, TFP growth (which they call residual-neutral technological change) had virtually no impact on the long term performance of the U.S. economy, at least not since the mid-1970s. Carlaw and Kosempel (2001) found similar results for Canada.

Although Observation 4 pertains to advanced countries, it is still relevant to the current analysis, since the objective is to describe the entire transition path of a developing economy. Combined the four stylized facts listed above indicate that as an economy transits towards its balanced growth path, the contributions of factor accumulation, technological progress and TFP growth to overall growth change. To preview the results, the model's predictions were found to be consistent with the findings of Greenwood et al. ${ }^{1}$ For example, in the model, TFP growth slows as an economy exits the transition period, and investment-specific technological change is required to produce a positive slope to the balanced growth path. The intuition for these results are as follows: When an economy reaches its balanced growth path, the rate of technological progress and human capital accumulation are the same. This implies that the rate at which workers are accumulating new knowledge is just sufficient to

\footnotetext{
${ }^{1}$ In the Greenwood et al. (1997) paper, TFP growth is assumed to be exogenous and independent of the rate of investment-specific technological change. These assumptions will be relaxed in the current paper.
} 
maintain their productivity in the workplace. Although new technologies do not lead to productivity improvements in the steady state, they do reduce the cost of acquiring capital, and therefore they are capable of sustaining a positive growth rate in the long run.

The remainder of the paper is organized as follows: The relevant literature is reviewed in Section 2. The model is constructed and its predictions for development and long run growth are discussed in Section 3. Concluding remarks are provided in Section 4.

\section{The Literature}

Romer (1993) and Zeng (1997) divide the literature on endogenous growth theory into two categories: capital-based and idea-based.

Capital-based theories focus on modelling the endogenous accumulation of physical and/or human capital (e.g., Arrow, 1962; Uzawa, 1965; Romer, 1986; Lucas, 1988; Rebelo, 1991). Idea-based theories focus on endogenous technological progress resulting from research and development (R\&D) as the source of growth (e.g., Romer, 1990; Grossman and Helpman, 1991; Aghion and Howitt, 1992). The current paper fits best among the capital-based theories; despite the fact that technological change, as well as human capital accumulation, plays a role in the development process. In the model, human capital accumulation is endogenous, since worker productivity in the learning sector rises the further behind knowledge is from the technology frontier. 
However, technological change will remain essentially exogenous, since the inputs into it will be held fixed as a percentage of GDP.

In that this paper models the relationship between human capital and technological change jointly, the theory resembles the works of Stockey (1988), Easterly et al. (1994), Parente (1994), Eicher (1996), Lloyd-Ellis (1999), Galor and Moav (2000), Acemoglu and Zilibotti (2001), Jones (2002) and Lloyd-Ellis and Roberts (2002). A brief description of these papers will be provided in the remainder of this section.

The two papers most closely related to this one are Jones (2002) and Lloyd-Ellis and Roberts (2002). The paper by Jones is strictly a growth accounting exercise, in which the inputs into R\&D and human capital accumulation are exogenous. However, his formulation of the production function residual is similar. In both his paper and this one, TFP growth depends positively on the stock of human capital and negatively on the current state of technology. In the Lloyd-Ellis and Roberts paper, the inputs into both R\&D and human capital are endogenous, however, they only characterize the balanced growth path. ${ }^{2}$ The current paper lies in between Jones and Lloyd-Ellis and Roberts in that the human capital side is endogenous but it is still possible to characterize the transitional dynamics.

There is also a sense in which the Lloyd-Ellis and Roberts paper and this one are complementary. In their paper, growth arises primarily via the

\footnotetext{
${ }^{2}$ In the Roberts and LLoyd-Ellis paper, rapid accumulation of one type of knowledge stimulates the accumulation of the other via the distribution of wages.
} 
creation of new technologies (the product of the $R \& D$ sector). Although the current paper also has an $\mathrm{R} \& \mathrm{D}$ sector, growth arises primarily via the process of technology adoption. Thus, their paper is likely to provide a better description of growth in very advanced countries; whereas the current paper is likely to provide a better description of growth in developing countries, where technology adoption is likely to play a large role in the growth process.

Next, the paper by Acemoglu and Zilibotti (2001) attempts to explain productivity differences across countries by studying the interaction between skill and technology. In their paper, productivity depends on the quality of the match between the skill requirements of a technology and the skill-set of the workforce. They claim that productivity levels are higher in advanced countries because the match in better. One key feature that distinguishes their paper from the current paper is that in their model the level of human capital is fixed. Therefore, unlike the current paper, they have not studied the effects that the creation of new technologies have on the incentives to undertake human capital investments.

Next, the papers by Easterly et al. (1994) and Lloyd-Ellis (1999) incorporate both technological progress and human capital accumulation into a growth model, to identify the factors that affect the rate of technology adoption. However, in these papers the authors assumed that the marginal product of time devoted to learning does not depend on the rate of technological progress. Although this assumption may be appropriate for studying the current performance of less developed countries (LDCs), which 
employ technologies that are sufficiently far from the technology frontier; it is inappropriate for studying the dynamics of developing countries, which are in the process of catching up to the technology frontier. As agents learn, an economy may become more effective at using technologies that have already been developed. However, at some point additional learning will only be possible if the frontier expands, that is, if technology improves.

Finally, the papers by Stockey (1988), Parente (1994), Eicher (1996) and Galor and Moav (2000) all model technological innovations as the by-product of the process of human capital accumulation. Thus, in these papers the direction of causality runs from human capital accumulation to technological change. ${ }^{3}$ In comparison, in the current paper the direction of causality is reversed. Here new technologies are the product of R\&D activities, and it is these new technologies that create new opportunities for learning.

\section{The Model}

The economy to be studied is closed and populated by a continuum of identical and infinitely lived households with measure 1 . There is a single final good which is used for both consumption and investment and a continuum of intermediate-capital goods which are used exclusively for the production of the final good.

\footnotetext{
${ }^{3}$ Galor and Moav consider an additional feedback effect from technology to human capital levels. In their model, new technologies render old stills obsolete.
} 


\subsection{Preferences}

The lifetime utility function of the representative household is given by,

$$
\sum_{t=0}^{\infty} \beta^{t} \ln C_{t}
$$

where $0<\beta<1$ is the discount factor and $C_{t}$ denotes the date $t$ level of consumption. The period budget constraint is given by

$$
C_{t}+\int_{0}^{N} p_{i, t} Q_{i, t+1} K_{i, t+1} d i \leq w_{t} A_{t} L_{t}+\int_{0}^{N} r_{i, t} Q_{i, t} K_{i, t} d i+\int_{0}^{N} \pi_{i, t} d i
$$

All types of expenditure and sources of income are measured in units of the consumption good. Total physical capital investment expenditures are given by $\int_{0}^{N} p_{i, t} Q_{i, t+1} K_{i, t+1} d i$; where $N$ denotes the measure of capital (or intermediate) goods available, $p_{i, t}$ denotes the purchase price of the $i$ th type of capital relative to the price of the final good, $Q_{i, t+1} K_{i, t+1}$ denotes the quantity purchased of the $i$ th type of capital (in efficiency units), and $Q_{i, t+1}$ is an index of quality. Households have three sources of income. First, each household is endowed with one unit flow of time which may be supplied to the production sectors, or devoted to human capital accumulation activities. Households receive a wage rate of $w_{t} A_{t}$ per unit of time $\left(L_{t}\right)$ that they supply to the production sectors, where $A_{t}$ denotes the effectiveness of labor at operating high-technology capital goods. Second, households supply capital to firms, and receive a rental rate of $r_{i, t}$. Finally, households have ownership of the intermediate-capital producers, and therefore receive a share of each firm's 
profits, $\pi_{i, t} \cdot{ }^{4}$

\subsection{Final Good Production}

The final good producing sector consists of a continuum of identical producers with locations of the interval $[0,1]$. The final good production uses labor and capital as inputs, subject to a constant returns to scale technology with the Cobb-Douglas form,

$$
Y_{t}=\left(A_{t} L_{t}\right)^{1-\alpha}\left(Q_{t} K_{t}\right)^{\alpha}
$$

Here $A_{t}^{1-\alpha}$ is TFP, $Q_{t} K_{t}$ is an index denoting the aggregate effective capital stock and $Q_{t}$ denotes the average quality of the capital stock or the current aggregate state of technology. The index of aggregate capital is defined as

$$
Q_{t} K_{t} \equiv\left[\int_{0}^{N}\left(Q_{i, t} K_{i, t}\right)^{\omega} d i\right]^{1 / \omega}
$$

where $Q_{i, t} K_{i, t}$ is the available stock of the $i$ th type of capital, and $0<\omega<1$ determines the degree of substitution among the different types of capital. A higher $\omega$ implies that capital goods are better substitutes in production.

The effectiveness of labor at operating high-technology capital goods is determined by TFP. Following Nelson and Phelps (1966), it is assumed that this parameter depends positively on the stock of human capital $\left(H_{t}\right)$ and

\footnotetext{
${ }^{4}$ Two restrictions are imposded to ease the computation burden of the calculations: log-liner preferences and 100\% depreciation of capital each period. These kinds of restrictions will reduce the analysis of the dynamics of the system to a system of equations that can be explicitly solved by doing algebra.
} 
negatively on the sophistication of existing technology,

$$
A_{t}=\eta\left(\frac{H_{t}}{Q_{t}}\right)^{\theta}
$$

where $0<\theta<\alpha /(1-\alpha) .{ }^{5}$ This specification implies that new technologies will not be operated efficiently until an investment in learning is undertaken.

\subsection{Human Capital Production}

Agents can augment their productivity by devoting more time to learning. The accumulation of human capital follows:

$$
H_{t+1}=B\left(1-L_{t}\right) Q_{t}^{\varepsilon} H_{t}^{1-\varepsilon}
$$

where $0<\varepsilon<1$ and $1-L_{t}$ denotes time allocated to learning. This specification of the human capital production function exhibits diminishing returns to the existing stock of human capital. As a result, human capital will accumulate in the long run only if there is technological progress. The technology term, $Q_{t}$, is incorporated into the function to capture the idea that new technologies create new learning opportunities, and therefore offset the tendency for diminishing returns to set in. ${ }^{6}$

\footnotetext{
${ }^{5}$ This restriction insures that it is never optimal to postpone the introduction of a new technology.

${ }^{6}$ The human capital production function adopted by Uzawa (1965) and Lucas (1988) can be considered a special case of (6), in which $\varepsilon=0$. Setting $\varepsilon=0$ is, however, somewhat unrealistic. It implies that a given percentage increase in human capital requires the same amount of learning-time, no matter what level of $H_{t}$ has already been attained. One would think, however, that if technology were to remain constant then eventually the opportunities for further learning would completely vanish.
} 


\subsection{Intermediate-Capital Goods Production}

Each capital good is produced by a monopolist. Capital goods become productive one period after the period in which they were produced/sold. Each physical unit of capital $\left(K_{i}\right)$ can be produced at a cost of one unit of the final good. The period profits of an intermediate-capital producer are given by

$$
\pi_{i, t}=(1-s)\left(p_{i, t} Q_{i, t+1} K_{i, t+1}-K_{i, t+1}\right)
$$

where $s$ denotes the share of gross profits that intermediate-capital producers reinvest in $\mathrm{R} \& \mathrm{D}$ activities and $p_{i, t}$ is the conditional factor demand function for capital good $i,^{7}$

$$
p_{i, t}=\left(\int_{0}^{N} p_{j, t}^{-\frac{\omega}{1-\omega}} d j\right)^{-\frac{1-\omega}{\omega}}\left(Q_{t+1} K_{t+1}\right)^{1-\omega}\left(Q_{i, t+1} K_{i, t+1}\right)^{-(1-\omega)} .
$$

The optimal pricing strategy for the $i$ th capital good producer is determined by choosing $K_{i, t+1}$ to maximize (7); taking as given the prices of the other producers, the aggregate demand for capital $\left(Q_{t+1} K_{t+1}\right)$ and the firm's current technology level $\left(Q_{i, t+1}\right)$. Substituting (8) into (7) and maximizing gives the condition,

$$
p_{i, t}=\frac{1}{\omega Q_{i, t+1}}
$$

This states that the optimal pricing strategy requires each intermediate-capital producer to charge a constant markup over its marginal cost. Substituting (8)

\footnotetext{
${ }^{7}$ The technical appendix describes the derivation of the conditional factor demand functions.
} 
and (9) into (7) gives

$$
\begin{aligned}
\pi_{i, t} & =(1-s)\left(\frac{1}{\omega}-1\right) K_{i, t+1} \\
& =(1-s)\left(\frac{1}{\omega}-1\right) Q_{t+1} K_{t+1}\left(\int_{0}^{N} Q_{j, t+1}^{\frac{\omega}{1-\omega}} d j\right)^{-\frac{1}{\omega}} Q_{i, t+1}^{\frac{\omega}{1-\omega}}
\end{aligned}
$$

This states that profits are positively related to the aggregate amount of capital demanded, negatively related to the technology of the other firms and positively related to each firm's own technology. Equation (10) indicates that a firm's profits rise when it develops a new technology, and this is true despite the fact that price falls in proportion to the increase in technology. Profits rise because price reductions lead to increases in demand.

The computer market provides an excellent example of the type of price-quantity movement predicted by the model. Computer processing speeds have been increasing rapidly; despite the fact that new computes are manufactured in about the same way, are constructed from just about the same assortment of metals, plastics and other raw materials and are sold for about the same price as older models. Although the price of a physical unit of capital (i.e. one computer) has remained roughly constant, the price per efficiency unit has been falling, and as a result the demand for computers has been rising.

\subsection{Research and Development}

The model follows Aghion and Howitt (1992) by assuming that R\&D activities are targeted at improving the quality of existing products, as 
opposed to creating entirely new products. It is assumed that incumbent firms have a lifetime patent, and therefore have the exclusive rights to produce and sell their product. Thus, the model considers only R\&D that is conducted by existing firms. In comparison, Aghion and Howitt assumed that all R\&D is conducted by entering firms. In the current paper, a new technology does not destroy the old, as it does in Aghion and Howitt's Model of Creative Destruction, it simply improves on the old.

The share of gross profits that firms invest in $\mathrm{R} \& \mathrm{D}, s$, is determined exogenously. However, since future profits are positively related to future technology levels, endogenizing $s$ is feasible. The decision to model $s$ as an exogenous parameter was done in part to ease the calculations, and in part to reduce the importance of $R \& D$ expenditures to the development process. This latter point requires additional clarification. Most $R \& D$ is conducted within a handful of countries: France, German, Japan, the United Kingdom and the United States. These are the countries that are primarily responsible for extending the technology frontier. However, since new technologies are embodied in physical capital and these goods can be imported; then poor countries should also have access to advanced technologies, despite the fact that they may not actually be undertaking their own R\&D. Since research intensity is exogenous, the model will not rely on this variable as an explanation for economic development.

The quality indexes are assumed to follow laws of motion given by

$$
Q_{i, t+1}=Q_{i, t} f(s), \forall i, \text { with }
$$




$$
f(0)=1, f^{\prime}(s)>0, f^{\prime \prime}(s)<0, \lim _{s \rightarrow 0} f^{\prime}(s)=\infty \text { and } \lim _{s \rightarrow 1} f^{\prime}(s)=0 .
$$

Since the objective of the paper is to describe a theory of development and growth, the model abstracts from sources of uncertainty, which would be important for business cycle analysis. Finally, it is assumed that quality differences between producers were initially uniformly distributed on the interval $Q_{0,0} \rightarrow Q_{N, 0}$. The structure of the model will ensure that the distribution does not change over time.

\subsection{Equilibrium}

Denote the state by $z=\left(\left\{Q_{i}\right\}_{i=0}^{N},\left\{K_{i}\right\}_{i=0}^{N}, Q, K, H\right)$ where time subscripts are dropped and a prime $\left(^{\prime}\right)$ will be used to denote next-period values. Suppose that prices can be written as functions of the state: $\left\{p_{i}=p_{i}(z)\right\}_{i=0}^{N},\left\{r_{i}=r_{i}(z)\right\}_{i=0}^{N}, w=w(z)$. Furthermore, suppose that the laws of motion for $\left\{Q_{i}^{\prime}\right\}_{i=0}^{N},\left\{K_{i}^{\prime}\right\}_{i=0}^{N}, Q^{\prime}, K^{\prime}, H^{\prime}$ are described by the policy functions $\left\{Q_{i}(z)\right\}_{i=0}^{N},\left\{K_{i}(z)\right\}_{i=0}^{N}, Q(z), K(z), H(z)$, respectively.

The problem faced by the representative household is to choose consumption $(\hat{C})$, stocks of physical $\left(\hat{K}^{\prime}\right)$ and human capital $\left(\hat{H}^{\prime}\right)$ and an allocation of time to the production of the final good $(\hat{L})$ and human capital $(1-\hat{L})$, which solve the following dynamic programming problem: ${ }^{8}$

$$
V\left(\left\{\hat{K}_{i}\right\}_{i=0}^{N}, \hat{H} ; z\right)=\max _{\hat{C},\left\{\hat{K}_{i}^{\prime}\right\}_{i=0}^{N}, \hat{H}^{\prime}, \hat{L}}\left\{\ln \hat{C}+\beta V\left(\left\{\hat{K}_{i}^{\prime}\right\}_{i=0}^{N}, \hat{H}^{\prime} ; z^{\prime}\right)\right\},
$$

\footnotetext{
${ }^{8} \mathrm{~A}$ circumflex $(\neg)$ indicates choices made by households, while an upside-down circumflex $(\smile)$ will denote final good producers decisions.
} 
subject to

$$
\begin{gathered}
\hat{C}+\int_{0}^{N} p_{i} Q_{i,}^{\prime} \hat{K}_{i}^{\prime} d i \leq w\left[\eta(\hat{H} / Q)^{\theta}\right] \hat{L}+\int_{0}^{N} r_{i} Q_{i} \hat{K}_{i} d i+\int_{0}^{N} \pi_{i, t} d i \\
\hat{H}^{\prime}=B(1-\hat{L}) Q^{\varepsilon} \hat{H}^{1-\varepsilon} .
\end{gathered}
$$

The problem faced by the representative final good producer is to maximize period profits through its choice of $\breve{L}$ and $\left\{\check{K}_{i}\right\}_{i=0}^{N}$ :

$$
\max _{\breve{L}_{,\left\{\breve{K}_{i}\right\}_{i=0}^{N}}}\left\{(A \breve{L})^{1-\alpha}\left[\int_{0}^{N}\left(Q_{i} \check{K}_{i}\right)^{\omega} d i\right]^{\alpha / \omega}-w A \breve{L}-\int_{0}^{N} r_{i} Q_{i} \check{K}_{i} d i\right\} .
$$

An equilibrium consists of policy functions $C=C(z), L=L(z)$, $\left\{Q_{i}^{\prime}=Q_{i}(z)\right\}_{i=0}^{N},\left\{K_{i}^{\prime}=K_{i}(z)\right\}_{i=0}^{N}, Q^{\prime}=Q(z), K^{\prime}=K(z), H^{\prime}=H(z)$; and price functions $\left\{p_{i}=p_{i}(z)\right\}_{i=0}^{N},\left\{r_{i}=r_{i}(z)\right\}_{i=0}^{N}, w=w(z)$; such that:

(i) households solve $(H P)$ taking as given the state-of-the-world and prices, with the solution to this problem being $\hat{C}=C(z), \hat{L}=L(z)$, $\hat{K}^{\prime}=K(z), \hat{H}^{\prime}=H(z)$

(ii) final good producers solve $(F P)$ taking as given the state-of-the-world and prices, with the solution to this problem being $\breve{L}=\hat{L}=L(z)$, $\breve{K}=\hat{K}$

(iii) the intermediate-capital producers solve their profit maximization problems, with the solutions being $\left\{p_{i}=p_{i}(z)\right\}_{i=0}^{N}$;

(iv) technology evolves according to equation (11); and

(v) the aggregate resource constraint is satisfied, ${ }^{9}$

$$
C+\frac{[1-(1-s)(1-\omega)]}{\omega} K^{\prime}=Y
$$

\footnotetext{
${ }^{9}$ The resource constraint is derived in the Appendix.
} 


\subsection{Policy Functions}

The policy functions that solve the household's dynamic optimization problem and satisfy the equilibrium conditions were derived via the guess-and-verify method. ${ }^{10}$ These functions are given by:

$$
\begin{aligned}
L_{t} & =\left[1+\frac{\beta \theta}{[1-\alpha \beta(1-s)(1-\omega)][1-(1-\varepsilon) \beta]}\right]^{-1}=L, \\
H_{t+1} & =B(1-L) Q_{t}^{\varepsilon} H_{t}^{1-\varepsilon}, \\
K_{t+1} & =\frac{\alpha \beta \omega \eta^{1-\alpha} L^{1-\alpha} H_{t}^{\theta(1-\alpha)} Q_{t}^{\alpha-\theta(1-\alpha)} K_{t}^{\alpha}}{1-\alpha \beta(1-s)(1-\omega)}, \\
K_{i, t+1} & =\frac{i^{\omega /(1-\omega)}}{(1-\omega) N^{1 /(1-\omega)}} \frac{\alpha \beta \omega \eta^{1-\alpha} L^{1-\alpha} H_{t}^{\theta(1-\alpha)} Q_{t}^{\alpha-\theta(1-\alpha)} K_{t}^{\alpha}}{1-\alpha \beta(1-s)(1-\omega)} \\
C_{t} & =\frac{(1-\alpha \beta) \eta^{1-\alpha} L^{1-\alpha} H_{t}^{\theta(1-\alpha)} Q_{t}^{\alpha-\theta(1-\alpha)} K_{t}^{\alpha}}{1-\alpha \beta(1-s)(1-\omega)} \\
Y_{t} & =\eta^{1-\alpha} L^{1-\alpha} H_{t}^{\theta(1-\alpha)} Q_{t}^{\alpha-\theta(1-\alpha)} K_{t}^{\alpha} .
\end{aligned}
$$

Although the savings decisions of the agents were determined

endogenously, equations (15) - (20) indicate that the agents always devote a constant fraction of their time to work and to learning, and a constant fraction of their output to consumption and physical capital investment. The fact that

${ }^{10}$ First, a guess was made that the value function is of the form:

$$
V\left(\left\{K_{i}\right\}_{i=0}^{N}, H ; z\right)=\rho_{0}+\rho_{1} \ln K+\rho_{2} \ln H+\rho_{3} \ln Q,
$$

where $\rho_{0}, \rho_{1}, \rho_{2}, \rho_{3}$ are constants. Second, the guess was updated one period and then substituted into Bellman's equation. Third, the Euler equations were derived (note that the rhos appear in these equations). Next, the guess was verified to be correct by finding the constants $\rho_{0}, \rho_{1}, \rho_{2}, \rho_{3}$ such that the guess satisfied Bellman's equation. The Contraction Mapping Theorem guarantees that if there exist values for the rhos that satisfy Bellman's equation then those values will be unique. Finally, the policy functions were derived by substituting the values of the rhos back into the Euler equations. 
the optimal savings behavior of the agents is independent of the capital stocks and the level of technology suggests that, in the model, changes to these variables have offsetting income and substitution effects on the incentives to work and to save. These offsetting effects are due to a combination of having a constant fraction of gross profits being allocated to R\&D, logarithmic utility, Cobb-Douglas production and 100 percent depreciation of capital. Despite the limited role that the savings rate plays in the analysis, the model will still provide a number of interesting insights into the time paths of human and

physical capital and TFP. It is the fact that the savings behavior of the agents is constant that will allow the model to be solved analytically. A nice feature of the model will be tractability of the transitional dynamics.

\subsection{Balanced Growth Transformation}

In the long run the aggregate state of technology and the stock of human capital must grow at the same rate - say $g_{q}$. This feature of the model is readily apparent by examining the human capital production function (16). If technology grows faster than human capital then the $Q / H$ ratio rises. This implies that more learning opportunities are becoming available, and therefore the marginal product of time devoted to learning is increasing, which in turn increases the rate of human capital accumulation. Eventually, the rate of human capital accumulation will catch up to the rate of technological change. The exact opposite happens if human capital initially grows faster than technology. 
Equations $(17)-(20)$ indicate that, in the model, the proportion of total expenditures allocated to physical capital and consumption do not change over time. In fact, the policy functions for physical capital and consumption are linear in output. Therefore, in the model $K, C$ and $Y$ must all grow at the same rate during both the transition to the steady state and in the steady state. As a result, by studying the dynamics of the physical capital stock, we also learn about the model's predictions regarding the time paths of consumption and output. The growth rate of output at date $t$ is given by

$$
g_{Y, t} \approx \theta(1-\alpha) g_{H, t}+[\alpha-\theta(1-\alpha)] g_{Q, t}+\alpha g_{K, t} .
$$

Imposing the long run restrictions that $g_{H}^{*}=g_{Q}$ and $g_{Y}^{*}=g_{K}^{*}$, gives the long run growth rate of output as a function of the rate of technological change,

$$
g_{Y}^{*} \approx \frac{\alpha}{1-\alpha} g_{Q}
$$

Star $\left(^{*}\right)$ superscripts are used throughout the paper to denote steady state values.

Note that the model's predictions regarding the sources of long term growth are consistent with the observations of Greenwood et al. (1997). ${ }^{11}$ Specifically, equation (22) indicates that investment-specific technological change is required to sustain long term growth. In the model, TFP does not represent a source of long term growth, and this is true despite the fact that human capital accumulates indefinitely. In the steady state, the rate of human capital accumulation is just sufficient to keep pace with the state of

\footnotetext{
${ }^{11}$ Refer to Section 1.
} 
technology, and therefore TFP is not improving.

\subsection{The Time Paths of the Capital Stocks}

To analyze the transitional dynamics of the model, it will be convenient to rewrite the system in terms of variables that remain constant in the steady state. Let:

$$
\begin{aligned}
h_{t} & =\frac{H_{t}}{Q_{t}}, \text { and } \\
k_{t} & =\frac{K_{t}}{Q_{t}^{\frac{\alpha}{1-\alpha}}} .
\end{aligned}
$$

The transformed variables $(h, k)$ are stationary in the steady state. Note that the rate of TFP growth is proportional to the growth rate of the variable $h$, and therefore the transitional dynamics of these variables are qualitatively the same.

Substituting (23) and (24) into (16) and (17) gives:

$$
\begin{aligned}
\frac{h_{t+1}}{h_{t}} & =\left[\frac{B(1-L)}{e^{g_{Q}}}\right] h_{t}^{-\varepsilon}, \text { and } \\
\frac{k_{t+1}}{k_{t}} & =e^{-\left(\frac{\alpha}{1-\alpha}\right) g_{Q}}\left[\frac{\alpha \beta \omega \eta^{1-\alpha} L^{1-\alpha}}{1-\alpha \beta(1-s)(1-\omega)}\right] h_{t}^{\theta(1-\alpha)} k_{t}^{-(1-\alpha)} .
\end{aligned}
$$

Equations (25) and (26) together form a system of two difference equations in $h$ and $k$. This system together with the initial conditions, $h_{0}$ and $k_{0}$, determines the time paths of $h$ and $k$. To analyze the dynamics of the model, a phase diagram is constructed in $(h, k)$ space in Figure 1. The arrows show the direction of motion for both $h$ and $k$. To the left of the $h_{t+1}=h_{t}$ locus, human capital is scarce relative to the aggregate state of technology, and therefore the marginal product of time devoted to learning is high. As a result, 


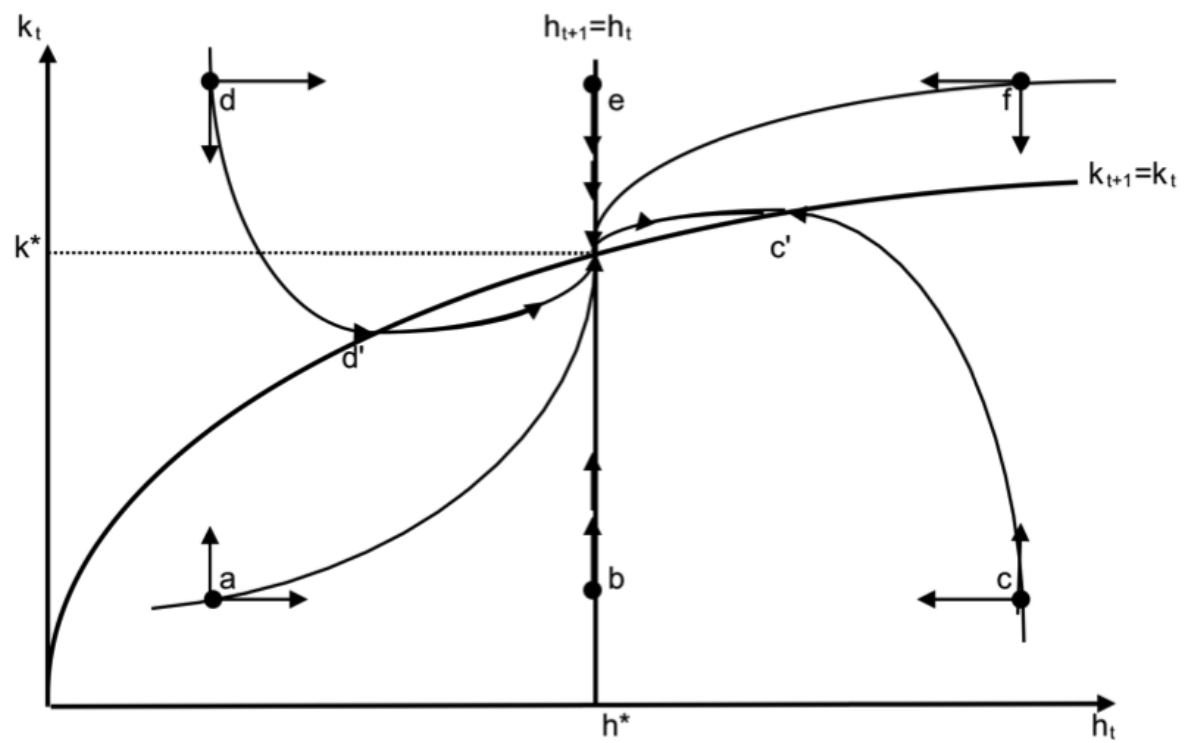

Figure 1: The Phase Diagram of the Model

$h$ is rising in this region and the arrows point to the right. At points to the right of the $h_{t+1}=h_{t}$ locus, human capital is relatively abundant, and therefore the marginal product of time devoted to learning is low. As a result, $h$ is falling in this region and the arrows point to the left. At points above the $k_{t+1}=k_{t}$ locus, physical capital is abundant relative to human capital, and therefore the marginal product of physical capital is low. As a result, $k$ is falling in this region and the arrows point down. At points below the $k_{t+1}=k_{t}$ locus, physical capital is relatively scarce, and therefore the marginal product of physical capital is high. As a result, $k$ is rising in this region and the arrows point up. 
In the phase diagram the shapes of the optimal paths are sensitive to the values of the model's parameters, and in particular the values of $\alpha, \theta$, and $\varepsilon$. These parameters play an important role in determining the convergence rates of the human and physical capital stocks. The paths displayed in Figure 1 were drawn assuming that, for a given technology level, human capital accumulation is subject to sharply diminishing returns. ${ }^{12}$ As a result, in this example human capital converges relatively quickly to its steady state.

However, it is possible that the rate of convergence of the human capital stock $(\varepsilon)$ differs between countries. ${ }^{13}$ The optimal paths for a country with a low value of $\varepsilon$ would be steeply sloped initially, and would then flatten out as the steady state is approached.

The trajectories in the phase diagram indicate that the steady state is a stable node. This property of the model can be verified by log-linearizing the system of dynamic equations and noting that the roots of the characteristic matrix are positive real numbers between 0 and 1 . The log-linearized version of equations (25) and (26) are examined in detail in the Appendix. The time paths of $\ln h_{t}$ and $\ln k_{t}$ are also calculated algebraically in the Appendix. The results of these calculations were used below to determine expressions for the

\footnotetext{
${ }^{12}$ Arrow (1962) imposed a similar assumption in his learning-by-doing model - learning associated with repetition of essentially the same problem is subject to sharply diminishing returns.

${ }^{13}$ Rosenberg (2000, chapter 3) compares the structure of American and European Universities. His finding lead him to conclude that American Universities have been especially successful as producers of economically useful knowledge and in achieving a rapid rate of diffusion of potentially useful knowledge.
} 
average growth rates of the human and physical capital stocks over an interval of length $T$. These expressions are given by:

$$
\begin{aligned}
& \frac{\ln \left(H_{T} / H_{0}\right)}{T}=g_{Q}+\left[\frac{1-(1-\varepsilon)^{T}}{T}\right] \ln \left(h^{*} / h_{0}\right), \text { and } \\
& \frac{\ln \left(K_{T} / K_{0}\right)}{T}=\left(\frac{\alpha}{1-\alpha}\right) g_{Q}+\left[\frac{1-\alpha^{T}}{T}\right] \ln \left(k^{*} / k_{0}\right)+ \\
&-\theta(1-\alpha)\left[\frac{\sum_{t=1}^{T} \alpha^{t-1}(1-\varepsilon)^{T-t}}{T}\right] \ln \left(h^{*} / h_{0}\right) .
\end{aligned}
$$

Consider first the transitional dynamics of the human capital stock. The phase diagram and equation (27) indicate that if $h^{*}>h_{0}$, then $h$ rises monotonically from its starting value to its steady state value. However, the average growth rate of $h$ falls as the length of the interval, $T$, rises. This is because the opportunities for learning diminish as the human capital to technology ratio approaches its steady state from below. The speed at which $h$ converges to its steady state equals $\varepsilon$. Once the steady state is attained, the stock of human capital grows at its long run rate, $g_{Q}$.

Now consider the transitional dynamics of the physical capital stock. Holding fixed the rate of technological change, $g_{Q}$, and the averaging interval, $T$; equation (28) indicates that the average rate of physical capital accumulation depends positively on the ratio of $k^{*}$ to $k_{0}$ and negatively on the ratio of $h^{*}$ to $h_{0}$. The first of these results is fairly standard in the growth literature. Low levels of capital imply a high marginal product of capital, and therefore a high rate of capital accumulation. The more interesting prediction of the model relates to the impact that human capital has on the accumulation of physical capital. 
Consider an economy that is endowed initially with a low level of physical capital. This would correspond, for example, to points $a, b$ or $c$ in the phase diagram. Each of these points are associated with the same stock of physical capital, but differ in the stocks of human capital. Notice that the shape of the trajectories at these points depend on the human capital to technology ratio, $h$. Suppose that the current stock of human capital is low, so that $h_{0}$ is less than $h^{*}$ - point $a$ in the diagram. The economy in this example consists of relatively unskilled workers. As a result, the factors of production have low marginal products, and therefore the physical capital stock grows slowly relative to an economy that has a larger endowment of human capital. The effect that a low stock of human capital has on the rate of physical capital accumulation is offset somewhat, but not completely, by the fact that a low stock of human capital also leads to high growth rates of human capital, and therefore higher future productivity levels.

Equation (28) indicates that the effect that human capital has on the average rate of physical capital accumulation is sensitive to the parameters $\theta(1-\alpha)$ and $\varepsilon$. The term $\theta(1-\alpha)$ governs the importance of $h$ to the production of output, and therefore to the marginal product of physical capital. As such, a larger value for $\theta(1-\alpha)$ would increase the sensitivity of the average rate of physical capital accumulation to deviations of $h_{0}$ from $h^{*}$. The parameter $\varepsilon$, on the other hand, governs the rate at which $h$ converges to its steady state. As such, a larger value of this parameter would reduce the sensitivity of the average rate of physical capital accumulation to deviations of 
$h_{0}$ from $h^{*}$.

Note that the model's predictions regarding the role of human capital in economic development are consistent with the empirical observations of Islam (1995) and Benhabib and Spiegel (1994). ${ }^{14}$ When human capital is abundant:

(i) TFP is high, and therefore per capita output grows rapidly; and (ii) productivity in the learning sector is low, and therefore human capital accumulates slowly. Thus, the model predicts a positive relationship between the initial level human capital, the initial level of TFP and rate of GDP growth; and a negative relationship between the rate of human capital accumulation and the rate of GDP growth. Just like we observe in the data.

There are a couple of other points in the phase diagram worth discussing. For example, consider an economy that is physical capital poor but human capital rich - point $c$. The marginal product of physical capital is very high for an economy located at point $c$, and therefore this economy initially experiences a very rapid rate of physical capital accumulation. In fact, physical capital is so productive initially that it is actually optimal for the economy to overshoot the steady state value, $k^{*}$. An economy that starts at point $c$ will grow initially at a rate well above its long run growth rate. However, as the economy transits along the trajectory from $c$ to the steady state, the marginal product of physical capital falls, and therefore the rate of physical capital accumulation declines. At $c^{\prime}$ the economy achieves its long run growth rate, but only temporarily. At this point there is actually too much physical capital

\footnotetext{
${ }^{14}$ Refer to Section 1.
} 
relative to the amount of human capital available, and therefore the rate of physical capital accumulation falls temporarily below its long run value.

However, as the economy nears its steady state, its growth rate gradually rises back to its long run level.

Finally, consider an economy that has an initial stock of physical capital that exceeds its steady state value, but a stock of human capital that is less than its steady state value - point $d$. At point $d$ the marginal product of physical capital is very low. As a result, the economy grows at a rate below its steady state growth rate until it reaches point $d^{\prime}$. As the economy transits along the trajectory from $d$ to the steady state, it accumulates human capital quickly, and therefore TFP is improving. At $d^{\prime}$ the economy has accumulated enough human capital to warrant a relatively high rate of physical capital accumulation. However, as the economy approaches the steady state the rate of physical capital accumulation slows and approaches its long run value.

\section{Conclusion}

The model in this paper provides a tractable analysis of the transitional dynamics of per capita output, human and physical capital accumulation and TFP growth. The model was shown to be consistent with the four empirical observations that were presented in the introduction. First, the model predicts conditional convergence. This implies that countries with identical preferences and technologies will converge to a common steady state, where they will have 
the same level and growth rate of per capita output. Second, higher initial levels of TFP were found to lead to higher initial growth rates, ceteris paribus. Third, during the transition interval, the growth rate of per capita output was positively related to the initial level of human capital, but negatively related to the rate of human capital accumulation. Finally, during the process of economic development the relative importance of the various factors contributing to growth changed. During the early stages of development, factor accumulation and TFP growth played a large role. However, as an economy exited the transition period, TFP growth slowed and technological progress was required to maintain a positive growth rate for output in the long run.

The Law of Diminishing Returns implies that the marginal product of capital is higher in less developed (capital-poor) countries. If so, then these countries should have relatively high growth rates. In the data, however, this is not always the case. The model has identified two factors that may be responsible for the unusually slow growth experienced by some LDCs. First, these countries may be poor at innovating, and therefore their technology grows slowly. This explanation is, however, somewhat unsatisfactory; since new technologies are embodied in physical capital and these goods can be imported from developed economies. The fact that we do not observe LDCs importing a lot of capital embodying advanced technologies suggests that there exist barriers that prevent trade from occurring. The model has identified one such barrier - the Knowledge Barrier. This relates to second explanation provided by the model for the slow growth experienced by LDCs. 
Specifically, these countries may be poorly endowed with human capital, a factor that is complementary to physical capital. Despite the fact that LDCs have a scarcity of physical capital, the marginal product of their capital may not actually be that high. Obviously, if the labor force is deficient in the skills required to effectively operate high-technology capital goods, then the optimal quantity of those goods that are imported will be low.

The average growth rates of the human and physical capital stocks were found to depend on the human capital convergence parameter, $\varepsilon$. Specifically, the model predicts that economies with a low value of $\varepsilon$ will be the slowest to adapt to new technologies and will experience the slowest transitions to the steady state, ceteris paribus. Although the model in this paper has identified the human capital convergence coefficient as a possible explanation for the low growth rates that have been sustain by LDCs; in order to make specific policy recommendations to help these economies, microeconomic research into the factors that affect the value of $\varepsilon$ is required. 


\section{A Appendix}

\section{A.1 The Conditional Factor Demand Functions}

The conditional factor demand functions were derived by choosing the quantity of each intermediate-capital good to minimize the cost of acquiring a given amount of aggregate capital,

$$
\min _{\left\{Q_{i, t+1} K_{i, t+1}\right\}_{i=0}^{N}} \int_{0}^{N} p_{i, t} Q_{i, t+1} K_{i, t+1} d i
$$

subject to

$$
Q_{t+1} K_{t+1}=\left[\int_{0}^{N}\left(Q_{i, t+1} K_{i, t+1}\right)^{\omega} d i\right]^{1 / \omega} .
$$

The solution to this problem is given by

$$
p_{i, t}=\left(\int_{0}^{N} p_{j, t}^{-\frac{\omega}{1-\omega}} d j\right)^{-\frac{1-\omega}{\omega}}\left(Q_{t+1} K_{t+1}\right)^{1-\omega}\left(Q_{i, t+1} K_{i, t+1}\right)^{-(1-\omega)} .
$$

If each firm behaves optimally, so that $p_{i, t}=\frac{1}{\omega Q_{i, t+1}}$, then (8) simplifies to

$$
Q_{i, t+1} K_{i, t+1}=\left(\int_{0}^{N}\left(\frac{Q_{i, t+1}}{Q_{j, t+1}}\right)^{\frac{\omega}{1-\omega}} d j\right)^{-\frac{1}{\omega}} Q_{t+1} K_{t+1} .
$$

Furthermore, given that quality grades are uniformly distributed, equation (8) can be simplified again,

$$
Q_{i, t+1} K_{i, t+1}=(1-\omega)^{-\frac{1}{\omega}} N^{-\frac{1}{\omega(1-\omega)}} i^{\frac{1}{1-\omega}} Q_{t+1} K_{t+1}
$$

\section{A.2 The Resource Constraint}

The resource constraint is derived as follows: First, let total physical capital investment expenditures be given by

$$
p_{t} Q_{t+1} K_{t+1}=\int_{0}^{N} p_{i, t} Q_{i, t+1} K_{i, t+1} d i
$$


where $p_{t}=\frac{1}{\omega Q_{t+1}}$ denotes the average price of a unit of aggregate capital.

Substituting (9) and (A3) into (A4) gives

$$
p_{t} Q_{t+1} K_{t+1}=\omega^{-1}(1-\omega)^{\frac{-(1-\omega)}{\omega}} N^{\frac{-1}{\omega}} Q_{N, t+1}^{-1} Q_{t+1} K_{t+1}
$$

where $Q_{N, t+1}$ denotes the quality of the most technologically advance type of capital and

$$
Q_{t+1}=(1-\omega)^{\frac{(1-\omega)}{\omega}} N^{\frac{1}{\omega}} Q_{N, t+1}
$$

is the average quality of the aggregate capital stock. Substituting (A3) and

(A6) into each firm's profit function and then integrating over all firms gives

$$
\int_{0}^{N} \pi_{i, t} d i=(1-s)\left(\frac{1}{\omega}-1\right) K_{t+1}
$$

Next, using the equilibrium conditions it can be shown that factor payments completely exhaust all output,

$$
w_{t} A_{t} L_{t}+\int_{0}^{N} r_{i, t} Q_{i, t} K_{i, t} d i=Y_{t}
$$

Finally, the resource constraint is obtained by substituting (A4), (A7) and

(A8) into the budget constraint (2),

$$
C+\frac{[1-(1-s)(1-\omega)]}{\omega} K^{\prime}=Y
$$

\section{A.3 The Time Paths of the Human and Physical Capital Stocks}

Log-linearizing equations (25) and (26) and converting to matrix notation gives: 


$$
\begin{aligned}
{\left[\begin{array}{c}
\ln h_{t+1} \\
\ln k_{t+1}
\end{array}\right]+\left[\begin{array}{cc}
\varepsilon-1 & 0 \\
-\theta(1-\alpha) & -\alpha
\end{array}\right]\left[\begin{array}{c}
\ln h_{t} \\
\ln k_{t}
\end{array}\right] } \\
=\left[\begin{array}{c}
\ln \left[\frac{B(1-L)}{e^{g Q}}\right] \\
\left(\frac{-\alpha}{1-\alpha}\right) g_{Q} \times \ln \left[\frac{\alpha \beta \omega \eta^{1-\alpha} L^{1-\alpha}}{1-\alpha \beta(1-s)(1-\omega)}\right]
\end{array}\right]
\end{aligned}
$$

The characteristic roots of the simultaneous difference equation system (A9) are $1-\varepsilon$ and $\alpha$. Since both roots are positive real numbers between 0 and 1 , the steady state is a stable node. The general solutions for the time paths of the human and physical capital stocks are given by:

$$
\begin{aligned}
\ln h_{t} & =\ln h^{*}-(1-\varepsilon)^{t} \ln \left(\frac{h^{*}}{h_{0}}\right) \text { and } \\
\ln k_{t} & =\ln k^{*}-\alpha^{t} \ln \left(\frac{k^{*}}{k_{0}}\right)-\frac{\theta(1-\alpha)}{1-\varepsilon-\alpha}\left[(1-\varepsilon)^{t}-\alpha^{t}\right] \ln \left(\frac{h^{*}}{h_{0}}\right) \\
& =\ln k^{*}-\alpha^{t} \ln \left(\frac{k^{*}}{k_{0}}\right)-\theta(1-\alpha)\left[\sum_{x=1}^{t} \alpha^{x-1}(1-\varepsilon)^{t-x}\right] \ln \left(\frac{h^{*}}{h_{0}}\right) .
\end{aligned}
$$

The steady state values, $h^{*}$ and $k^{*}$, are:

$$
\begin{aligned}
h^{*} & =\left[\frac{B(1-L)}{e^{g_{Q}}}\right]^{\frac{1}{\varepsilon}}, \text { and } \\
k^{*} & =\left[e^{-\left(\frac{\alpha}{1-\alpha}\right) g_{Q}} \times \frac{\alpha \beta \omega \eta^{1-\alpha} L^{1-\alpha}}{1-\alpha \beta(1-s)(1-\omega)} \times h^{* \theta(1-\alpha)}\right]^{\frac{1}{1-\alpha}} .
\end{aligned}
$$




\section{References}

Acemoglu, D., Zilibotti, F., 2001. Productivity differences. Quarterly Journal of Economics 116(2), 563-606.

Aghion, P., Howitt, P., 1998. Endogenous Growth Theory. MIT Press, Cambridge, Massachusetts.

Aghion, P., Howitt, P., 1992. A model of growth through creative destruction. Econometrica 60(2), 323-351.

Arrow, K.J., 1962. The economic implications of learning by doing. Review of Economic Studies 29(3), 155-173.

Barro, R.J., Sala-i-Martin, X., 1992. Convergence. Journal of Political Economy 100(2), 223-251.

Barro, R.J., Sala-i-Martin, X., 1991. Convergence across states and regions. Brookings Papers on Economic Activity 1991(1), 107-158.

Benhabib, J., Spiegel, M.M., 1994. The role of human capital in economic development: evidence from aggregate cross-country data. Journal of Monetary Economics 34(2), 143-173.

Carlaw, K., Kosempel, S., 2001. Accounting for Canada's economic growth. Discussion Paper No. 2001-1, University of Guelph.

Easterly, W., King, R., Levine, R., Rebelo, S., 1994. Policy, technology adoption and growth. Working Paper No. 4681, National Bureau of Economic Research. 
Eicher, T.S., 1996. Interaction between endogenous human capital and technological change. Review of Economic Studies 63(1), 127-144.

Galor, O., Moav, O., 2000. Ability-biased technological transition, wage inequality, and economic growth. Quarterly Journal of Economics $115(2), 469-497$.

Greenwood, J., Hercowitz, Z., Krusell, P., 1997. Long-run implications of investment specific technological change. American Economic Review 87(3), 342-362.

Grossman, G.M., Helpman, E., 1991. Quality ladders in the theory of growth. Review of Economic Studies 58(1), 43-61.

Islam, N., 1995. Growth empirics: a panel data approach. Quarterly Journal of Economics 110(4), 1127-1170.

Jones, C.I., 2002. Source of U.S. economic growth in a world of ideas. American Economic Review 92(1), 220-239.

Lloyd-Ellis, H., Roberts, J., 2002. Twin engines of growth: skills and technology as equal partners in balanced growth. Journal of Economic Growth 7(2), 87-115.

Lloyd-Ellis, H., 1999. Endogenous technological change and wage inequality. American Economic Review 89(1), 47-77.

Lucas, R.E. Jr., 1990. Why doesn't capital flow from rich to poor countries?. American Economic Review 80(2), 92-96. 
Lucas, R.E. Jr., 1988. On the mechanics of economic development. Journal of Monetary Economics 22(1), 3-42.

Mankiw, N.G., Romer, D., and Weil, D.N., 1992. A contribution to the empirics of economic growth. Quarterly Journal of Economics 107(2), $104-437$.

Nelson, R.R., Phelps, E.S., 1966. Investment in humans, technological diffusion, and economic growth. American Economic Review 61, 69-75.

Parente, S., 1994. Technology adoption, learning by doing and economic growth. Journal of Economic Theory 63(2), 346-369.

Rebelo, S., 1991. Long-run policy analysis and long-run growth. Journal of Political Economy 99(3), 500-521.

Romer, P.M., 1993. Two strategies for economic development: using ideas and producing ideas. Proceedings of the World Bank Annual Research Conference 1992, World Bank Economic Review (Supplement), 63-91.

Romer, P.M., 1990. Endogenous technological change. Journal of Political Economy 98(5), S71-S102.

Romer, P.M., 1986. Increasing returns and long-run growth. Journal of Political Economy 94(5), 1002-1037.

Rosenberg, N., 2000. Schumpeter and the Endogeneity of Technology: Some American Perspectives. Routledge, New York. 
Stockey, N., 1988. Learning by doing and the introduction of new goods. Journal of Political Economy 96(4), 701-708.

Uzawa, H., 1965. Optimal technical change in an aggregate model of economic growth. International Economic Review 6(1), 18-31.

Zeng, J., 1997. Physical and human capital accumulation, R\&D and economic growth. Southern Economic Journal 63(4), 1023-1038. 